\title{
Los cuidados de larga duración y el cuarto pilar del sistema de bienestar ${ }^{1}$
}

\author{
Long Term Care, and the Fourth Pillar of the \\ Welfare State
}

\author{
Dolors COMAS D'ARGEMIR \\ Universitat Rovira i Virgili \\ dolors.comasdargemir@urv.cat
}

Recibido: 14 de marzo de 2014

Aceptado: 26 de noviembre de 2014

\begin{abstract}
Resumen
Este artículo analiza las políticas públicas de atención a los cuidados de larga duración que se han desarrollado en España a partir de su concreción en Cataluña. Estas políticas suponen un cambio en la distribución del cuidado entre familia, Estado y mercado. Se llega a tres conclusiones básicas. La primera es que las políticas públicas son un complemento y no una sustitución de lo que hace la familia, que sigue manteniendo funciones asistenciales de primera magnitud. La segunda es que la implicación del Estado no va en detrimento del mercado, sino todo lo contrario: la expansión del mercado se refuerza. En tercer lugar, las políticas públicas no alteran la estructura de género, pues las mujeres siguen siendo las principales responsables del cuidado de personas adultas dependientes y los hombres apenas se implican en él. Estas políticas se han visto truncadas por la profunda crisis económica que se está viviendo actualmente. La naturalización de los cuidados como actividades propias de las mujeres se ha reinstaurado en la práctica por medio de los recortes presupuestarios y en derechos sociales.
\end{abstract}

Palabras clave: dependencia; cuidados; género; políticas sociales; mercantilización; discapacidad; envejecimiento; prestaciones sociales.

\begin{abstract}
This article analyses the Spanish and especially Catalan public policies for long term care. These policies change the distribution of care between family, state, and market. We have arrived at three main conclusions. Firstly, public policies complement and doesn't substitute the role of the family, which continues to have an important care role. Second, the involvement of the state does not decrease the market role. On the contrary, the market has expanded. Thirdly, public policies have not changed the gender structure. Women remain the principal caretaker and men are hardly ever involved. These policies have been halted because of the economic crisis. The social construction of women as care providers has been reinforced as the result of budget restrictions and diminished social rights.
\end{abstract}

${ }^{1}$ Esta investigación se incluye en el proyecto CSO2009-14763-C03-01 del Ministerio de Ciencia e Innovación, en el que analizaba la dimensión de los cuidados. En su redacción contó con el apoyo del Institute for Social Research, de Birkbeck College, Universidad de Londres, en el que estuve como investigadora invitada en el 2012. 
Keywords: dependency; care; gender; social policies; commoditisation; disability; ageing; social benefits.

Referencia normalizada: Comas d'Armegir, D. (2015) Los cuidados de larga duración y el cuarto pilar del sistema de bienestar, en Revista de Antropología Social 24, 375-404.

SUMARIO: 1. Introducción. 2. La distribución del cuidado. Familia, Estado y mercado. 3. La dependencia como construcción social: de la invisibilidad a la implicación pública. 4. Las personas destinatarias de los cuidados. 4.1. Las dependencias asociadas a la edad. 4.2. La especificidad de las personas con discapacidad. 5. Los poderes públicos. El modelo de intervención pública en Cataluña. 6. El mercado. Empresas privadas y empleadas domésticas. 7. La Ley de Dependencia, un trayecto frustrado nada más empezar. 8. Conclusiones. 9. Referencias bibliográficas.

\section{Introducción}

Las políticas para atender los cuidados de larga duración —identificadas en España como políticas de atención a la dependencia - modifican la idea de que el cuidado es un problema individual y familiar y asumen que se trata de un problema social que requiere el apoyo del Estado. Suponen, pues, una redistribución de las responsabilidades del cuidado. En este artículo analizaré el proceso por el que crecen en España las necesidades sociales vinculadas a los cuidados de larga duración y las políticas que se formulan para atenderlas a partir de cómo se concretan en Cataluña, pues el hecho de que los servicios sociales estén descentralizados hace que el acceso a los recursos públicos dependa de las políticas específicas de cada Comunidad Autónoma. Me interesa especialmente incidir en dos aspectos. Uno es cómo se alteran los flujos de los recursos de bienestar provistos por la familia, por el Estado y por el mercado. La segunda dimensión es cómo se articulan estas políticas con los patrones de género y hasta qué punto los modifican. Estos aspectos resultan esenciales para entender por qué el desmantelamiento actual de estas políticas no genera respuestas sociales contundentes.

La denominada Ley de Dependencia, aprobada en el año $2006,{ }^{2}$ se inscribe en la voluntad política de desarrollar un sistema de servicios sociales universal, y en la exposición de motivos de la ley se dice literalmente que "el desarrollo social de nuestro país ha venido a situar en un nivel de importancia fundamental a los servicios sociales [...] como cuarto pilar del sistema de bienestar, para la atención de las situaciones de dependencia". Esta ley se considera por tanto como un apuntalamiento de derechos sociales que ha de resolver las crecientes necesidades de cuidados de larga duración principalmente vinculados a las personas ancianas. Pero su aplicación en plena crisis económica hace que ya desde los inicios se aleje de sus objetivos programáticos, se modifiquen después en profundidad e incumpla la previsión de universalidad, de manera que aquel "cuarto pilar del sistema de bienestar" se deforma y debilita.

${ }^{2}$ Ley 39/2006, de 14 de diciembre, de promoción de la autonomía personal y atención a las personas en situación de dependencia. 
El análisis se inscribe en la consideración de las políticas públicas como fenómenos culturales en la medida que codifican normas sociales y valores y contienen explícita o implícitamente los símbolos dominantes que subyacen al sistema cultural. Son instrumentos del poder moderno que se presentan bajo un lenguaje técnico que enmascara las tensiones y mecanismos de dominación (Shore y Wright, 1997: 7-10). Esta perspectiva se aleja de la mera reproducción de las categorías y discursos utilizados en el lenguaje político-tecnocrático, como si este reflejara una racionalidad burocrática coherente y estable, y trata de identificar los modos de acción y los campos de tensión que vinculan las políticas a las prácticas sociales (Franzé, 2013: 14). Las políticas para atender los cuidados de larga duración se hallan en tensión con la denominada "crisis de los cuidados", lo cual permite analizar las políticas públicas desde una perspectiva crítica, en la medida en que pueden generar procesos mal ajustados o no equitativos (Sanday, 2013: 201).

La reproducción social es un concepto clave en la comprensión de que la producción de bienes y servicios y la reproducción de la vida son parte de un proceso integrado (Harris y Young, 1981). La ficticia separación entre trabajo productivo y trabajo reproductivo, que se materializa en una separación del ámbito laboral y el familiar y en una distribución de estos trabajos entre hombres y mujeres contribuye a la invisibilización y subordinación del trabajo reproductivo. Este constructo tan arraigado desde el advenimiento del capitalismo no se basa tanto en una descripción de cómo son las cosas sino que es una poderosa imagen que contribuye a que las cosas sean de esta manera, es decir, impregna la percepción social sobre los atributos de hombres y mujeres y restringe el trabajo reproductivo y las actividades de cuidado al ámbito familiar.

Las políticas públicas se basan en determinadas asunciones que aparecen como evidentes e inevitables y que actúan como máscaras que ocultan determinadas formas de dominación y de poder (Gledhill, 1999). La separación entre producción y reproducción constituye uno de los constructos sociales más poderosos de nuestro tiempo que, al considerarse natural e inevitable, no es cuestionado, a pesar de que las luchas feministas y las propias prácticas sociales lo desmientan. Las políticas públicas para atender los cuidados de larga duración que se han desarrollado en España se basan en esta asunción y esto se traduce en tres grandes máscaras que ocultan la dimensión social de los cuidados y su distribución desigual en términos sociales y de género.

Una de estas máscaras es la propia noción de dependencia, que se identifica con la necesidad de recibir cuidados en determinada situación vital, vinculada a la vejez o a la discapacidad, ocultando así que la necesidad de cuidados es algo generalizado en el ciclo de la vida de todas las personas aunque en algunos momentos se precisen más. Se refuerza así el valor de la autonomía y de la autosuficiencia personal que son uno de los mitos fundacionales de nuestro tiempo (Fineman, 2000, 2004). Por otro lado, al circunscribir los cuidados a determinados momentos del ciclo vital, se oculta su papel fundamental en la sostenibilidad de la vida y en la reproducción social.

Las políticas de atención a los cuidados de larga duración se asientan en que la familia es la principal responsable de sus miembros y esta es una segunda máscara, 
pues oculta que los cuidados conciernen al conjunto de la sociedad ya que afectan a la reproducción social. Es necesario remarcar este aspecto porque la noción de familia como ideal imaginario es un concepto muy potente y de gran utilidad potenciado por las políticas públicas, que alimentan y fomentan la naturalización de la familia, partiendo de la certeza de que esta es la principal suministradora de asistencia y bienestar. Como señala Fineman (2000: 14), "la familia es una construcción ideológica con una particular composición y relaciones de género que permite privatizar la dependencia individual y no considerarla como un problema público". Se trata pues de desvelar el mito del cuidado familiar como la solución óptima frente a otras opciones, como los servicios públicos o privados, que se ubican como subsidiarias y aparecen como menos deseables. Y se trata también de ser conscientes del rol que se atribuye a la familia y no darlo como algo dado.

La tercera máscara oculta unas determinadas relaciones de género, pues son las mujeres las que asumen mayoritariamente los cuidados a partir de una construcción social que naturaliza este papel, al que se añaden además el afecto y la dimensión moral. Esto incide en la participación desigual de mujeres y hombres en los ámbitos laborales, sociales y políticos, sin que se otorgue valor por otro lado a actividades ejercidas en el hogar y que son fundamentales para la reproducción social (Comas d'Argemir, 1995).

El análisis de las políticas públicas para atender a los cuidados de larga duración que desarrollo en este texto se inscribe en una investigación de largo recorrido sobre las actividades de cuidado, que inicié a mediados de los años noventa (Comas d'Argemir, 1994, 2000; Comas d'Argemir y Roca, 1996), que se ha reanudado recientemente con el estudio de las políticas públicas y que en la actualidad se centra en la implicación de los hombres en los cuidados. La investigación etnográfica que habíamos realizado inicialmente mostraba la importancia de las políticas públicas (por sus características o por su ausencia) en la asunción de los cuidados, lo que me llevó a entender que desde la antropología no teníamos que tomar las políticas públicas como algo dado, sino que debían ser objeto de estudio por sí mismas. Entre el año 2000 y el 2012 interrumpí la actividad académica y en mi calidad de diputada del Parlamento de Cataluña participé directamente en la elaboración de la Ley de Servicios Sociales de Cataluña e indirectamente en la de la Ley de Dependencia. Buena parte del material empírico de este artículo proviene de la observación y participación en la elaboración de políticas públicas, en la que difícilmente podía abandonar la mirada antropológica. Bien es cierto que en este texto no están presentes directamente las voces de los y las hacedoras de políticas públicas, pero sí lo están en las asunciones implícitas que han orientado la elaboración de textos normativos y su aplicación. Porque muchas de estas asunciones no se explicitan nunca. Y porque los efectos de la aplicación de las políticas no siempre son predecibles en todas sus dimensiones.

\section{La distribución del cuidado. Familia, Estado y mercado}

Las políticas para atender las situaciones de dependencia vinculadas al envejecimiento y a la discapacidad que se han desarrollado en Cataluña se han fundamentado 
en el reconocimiento del papel de la familia en los cuidados y la implicación de las mujeres se ha asumido como algo dado. Se trata de políticas que han favorecido la expansión del mercado a pesar del incremento de la responsabilidad pública. Mostraré cómo el estancamiento actual de esas políticas se apoya en la idea de que la familia y las mujeres responderán. Situación que, por cierto, constituye una formidable oportunidad para el mercado, ya que las necesidades de cuidados de larga duración van a seguir aumentando. Las dimensiones económicas del cuidado han adquirido visibilidad. Y también que los cuidados van más allá de las implicaciones personales. Son una cuestión de clase, de género y también étnica. Son una cuestión política.

Las políticas públicas para atender los cuidados de larga duración surgen a raíz de la denominada "crisis de los cuidados", motivada por la presencia masiva de mujeres en el mercado de trabajo y por el incremento de las situaciones de dependencia derivadas de la vejez o de la discapacidad. La respuesta de los hogares a las tensiones generadas por la presión de cuidar ha sido la externalización de los cuidados (sea en el mercado sea en instituciones públicas) y esto se ha relacionado a su vez con la internacionalización de la mano de obra, compuesta mayoritariamente por personas de origen extranjero. Las dimensiones de clase y étnicas aparecen así vinculadas al género (Carrasco, Borderías y Torns, 2011; Cerri y Alamillo-Martínez, 2012; Ezquerra, 2011; Mandell, 2010; Pérez Orozco, 2006).

La distribución social de los cuidados va más allá de lo que se hace en la familia, y ha de tomar en consideración las instituciones derivadas del Estado y del mercado, así como las asociativas o comunitarias. Efectivamente, en nuestra sociedad el Estado, a través de las políticas públicas, asume responsabilidad social en los cuidados mediante la provisión de servicios, de prestaciones económicas y de tiempo. También el mercado suministra servicios de cuidado mediante empresas privadas especializadas en este ámbito y mediante la contratación de cuidadoras en el hogar. Esta perspectiva más global, que abarca al conjunto de la sociedad plantea la necesidad de analizar la articulación de las dimensiones de género con las de clase y también con las étnicas. Se trata de analizar hasta qué punto la redistribución de los cuidados modifica las pautas de género y se vincula a cambios en la organización de la producción y de la reproducción, es decir, a la transformación de la sociedad y de sus estructuras de desigualdad.

La familia tiene una importante función asistencial. En ella se canalizan las actividades de cuidado y asistencia orientadas a proporcionar bienestar físico, psíquico y emocional a las personas. Integran aspectos como el apoyo económico, suministro de vivienda, cuidados a personas adultas, cuidados a niños y niñas, así como ayuda práctica y emocional. Se trata de actividades diversas y desiguales que pueden hacerse de forma continuada o esporádica según el ciclo vital de las personas o de coyunturas críticas. Sirven para resolver, en definitiva, los riesgos de adversidad y las situaciones de dependencia. Son mujeres las que asumen la mayor parte de estas tareas, tanto si se trata de cuidar a personas que no pueden valerse por sí mismas como a personas que sí pueden hacerlo. Son actividades que se hacen por afecto o por obligación moral, o por las dos cosas a la vez. Forman parte de lo que se ha denominado "economía del afecto" (Comas d'Argemir, 2000: 188) y que tiene un 
doble sentido: tienen valor económico (lo que queda de manifiesto cuando las realiza el mercado o el Estado) y, cuando se efectúan en el hogar, "economizan" gasto público (Carrasco, Borderías y Torns, 2011).

El género impregna la totalidad de estructuras de cuidados y constituye la variable más fecunda a la hora de interpretar los cuidados suministrados en la familia. Por su papel en la reproducción de la vida se atribuye a las mujeres determinadas capacidades y habilidades para cuidar y esto contribuye a que estén fuertemente naturalizadas. Queda así oculto que el aprendizaje es un componente básico en estas actividades, como muestra su gran variación intercultural, y queda oculto también que el amor y los sentimientos, que parecen tan espontáneos e instintivos, son expresiones de relaciones sociales. Es la atribución social de las responsabilidades familiares a las mujeres la que determina su rol en los cuidados y no su naturaleza especial. Esteban (2011: 70) reclama la necesidad de desenmascarar el hecho de que las mujeres sean consideradas emocionales en mayor medida que los hombres y en función de ello se les asigne el trabajo de cuidar. Además, el altruismo y el desinterés, que parecen ser atributos constitutivos de la familia, están desigualmente repartidos: hay tensiones y también intereses asociados al cuidado y, en todo caso, el altruismo tiene un componente económico.

En la familia se alcanzan compromisos negociados entre mujeres y hombres, que vienen condicionados por los factores que modelan las necesidades de cuidados y las capacidades para proporcionarlos, y la presencia o ausencia de políticas públicas condiciona alternativas y oportunidades (Finch, 1989: 236). Por esto es importante analizar hasta qué punto las políticas de cuidados de larga duración inciden en la corresponsabilidad de hombres y mujeres en el cuidado. De hecho, son políticas a favor de las mujeres, que pueden mejorar su situación, pero que no alteran necesariamente las relaciones de género (Peterson, 2007: 55). La hipótesis de partida es que las políticas de provisión pública de cuidados se formulan en base a la construcción social de las mujeres como cuidadoras, lo cual se ha reforzado especialmente en su aplicación.

El Estado, en su papel de redistribución social, expresa no solo las tensiones de género sino también las de clase. Así, las políticas basadas en el familismo como principal malla de protección social, fortalecen las opciones del mercado y desprotegen a la mayoría de la población. Se basan de hecho en una privatización de los cuidados en la familia que, de acuerdo con sus posibilidades económicas, puede externalizar o no los cuidados en el mercado. El objetivo es analizar cómo a partir de las políticas de atención a la dependencia se redistribuyen los cuidados entre familia, Estado y mercado y cómo esta redistribución incide en los ejes de desigualdad social.

\section{La dependencia como construcción social: de la invisibilidad a la implica- ción pública}

En la década de los años setenta se producen en Europa cambios profundos que alteran la división sexual del trabajo y que obligan a reformular cómo se organizan los cuidados, especialmente cuando se trata de cuidados de larga duración. Las 
respuestas de cada Estado son variadas, con mayor implicación pública en los países con mejor desarrollo del Estado del bienestar y donde las mujeres tienen mayor presencia social y política (como es el caso de Suecia, Noruega o Francia, por ejemplo) promoviendo unas políticas que combinan las prácticas familiares, la intervención del Estado (a partir de la universalización en el acceso de servicios y prestaciones) y las aportaciones individuales al costo de los servicios (Rodríguez Cabrero, 2011: 15). En España el debate social en torno a estas cuestiones y su entrada en la agenda política llegan más tarde. A finales de los años setenta se iniciaron políticas para la atención a las personas ancianas y a las personas con discapacidad, que alcanzarían un mayor desarrollo en las dos décadas siguientes, pero los cuidados no se habían construido como una cuestión social y eran asumidos mayoritariamente por las mujeres en el seno de la familia ${ }^{3}$. Es cierto que en 1988 se publicó el libro De puertas adentro, coordinado por Maria Ángeles Duran, que revelaba la cantidad de tiempo y de ahorro en gasto público que esto suponía, pero la conciencia de ello era minoritaria, bien difundida en el movimiento feminista, pero ausente del debate social hasta prácticamente veinte años después. Progresivamente se fue gestando la necesidad de corresponsabilidad pública en una cuestión que se consideraba un asunto individual y familiar.

A finales de los años 90, se promulgan en España algunas medidas encaminadas a favorecer los cuidados en el ámbito familiar, proporcionando tiempo para esta dedicación. Se trata de las políticas de conciliación de la vida familiar y laboral, promovidas desde la Unión Europea. El objetivo es aumentar y mejorar los permisos y excedencias, así como la reducción de jornadas, tanto para cuidar la primera infancia como a personas adultas dependientes, traspasando así tiempo laboral a tiempo de cuidados. La llamada Ley de Conciliación, aprobada en 1999, está pensada para que sean las mujeres las que deban conciliar y, en este sentido, tiende a reproducir las desigualdades en la división del trabajo entre hombres y mujeres ${ }^{4}$. Los contratos a tiempo parcial, mucho más frecuentes entre las mujeres, han sido utilizados por las empresas como parte de sus estrategias laborales y más allá de las necesidades de tiempo para cuidar. La Ley de Igualdad, aprobada en el 2007, establece medidas más equitativas entre mujeres y hombres, introduciendo un permiso de paternidad propio de los hombres, así como mejoras en excedencias y permisos ${ }^{5}$. Y en Cata-

${ }^{3}$ El Plan Gerontológico se inicia en 1992 y se renueva con el Plan de Acción para personas mayores 2003-2007. La Ley 13/1982, de 7 de abril, de Integración Social de los Minusválidos (LISMI) tiene como objetivos conseguir la realización personal y la integración laboral de las personas con discapacidades. El Plan Concertado de Prestaciones Básicas de Servicios Sociales de Corporaciones Locales se inicia en 1988 y establece las formas de cooperación entre el Estado, las Comunidades Autónomas y los ayuntamientos para la prestación de servicios sociales de atención primaria, de inclusión social, de promoción de las familias y de la infancia y de prevención de las situaciones de dificultad o conflicto social. Hay que citar también las prestaciones y subvenciones derivadas del sistema de la Seguridad Social.

${ }^{4}$ Ley 39/1999, de 5 de noviembre, para promover la conciliación de la vida familiar y laboral de las personas trabajadoras.

${ }^{5}$ Ley $3 / 2007$, de 22 de marzo, para la igualdad efectiva de mujeres y hombres. 
luña se introdujeron mejoras notables para los trabajadores de las administraciones públicas ${ }^{6}$.

Pronto se mostró que sin la presencia de servicios de proximidad (como escuelas para la primera infancia, servicios a domicilio, residencias asistidas o centros para personas con discapacidad, por ejemplo) y sin cambios en la organización de los horarios laborales, estas medidas orientadas a conseguir una mejor articulación de la vida familiar, laboral y personal, tenían una eficacia muy limitada. El tema de los cuidados de larga duración resultaba especialmente problemático, porque estaba originando fuertes dificultades para las familias y porque se constató que las necesidades de atención experimentaban un incremento progresivo. Proporciono estos referentes para situar la reflexión de cómo en los inicios del siglo XXI se empieza a construir en España un problema social, el de la atención a los cuidados de larga duración, que se identificaron con el término de atención a la dependencia. Distintos factores contribuyeron a ello:

Primero, factores de carácter demográfico: una muy baja natalidad, combinada con un fuerte aumento de la esperanza de vida, contribuyen a configurar una población envejecida, e incluso un "envejecimiento del envejecimiento". En Cataluña, en concreto, la población de personas mayores de 80 años pasa de 220.000 en 1995 a 313.000 en 2005 y a 425.000 en 2013. Y las tasas de fecundidad se mantienen bajas: 1,17 hijos por mujer en $1995 ; 1,42$ en $2005 ; 1,33$ en 2013 . El resultado es que la proporción de población mayor de 80 años respecto al total de población también aumenta: un $3,6 \%$ en 1995 ; un 4,7 en 2005 , un $5,7 \%$ en $2013^{7}$. Y esta proporción va a seguir aumentando.

Segundo, factores de carácter social. Las mujeres jóvenes están incorporadas mayoritariamente en el mercado laboral y no pueden asumir las responsabilidades familiares como lo hacía la familia tradicional y más en concreto las amas de casa. Cuando se tramitaba la Ley de Dependencia en el año 2006, en Cataluña la tasa de actividad de las mujeres entre 30 y 54 años era de 76,2 y asciende a 84,7 entre las mujeres más jóvenes, entre 25 y 29 años. En el año 2013 esta tasa se eleva a 85,5 y 85,7 respectivamente $^{8}$. La baja fecundidad existente está asociada con el retraso de la maternidad, de manera que el primer hijo se tiene alrededor de los treinta años, que es una edad cercana al momento en que empieza el riesgo de tener que ocuparse de personas mayores dependientes. La gestión del tiempo se convierte en una dimensión conflictiva y tensionante para las mujeres.

Tercero, factores de género: los hombres apenas se corresponsabilizaban en las tareas de cuidado. Así, en 2009-2010, los hombres dedican diariamente 1 hora 47 minutos al hogar y a la familia, mientras que las mujeres dedican más del doble: 4 horas, 7 minutos $^{9}$. Algunos hombres sí se implican en las actividades de crianza,

${ }^{6}$ Ley $8 / 2006$, de conciliación de la vida personal, familiar y laboral del personal al servicio de las administraciones públicas en Cataluña.

${ }^{7}$ Datos del Institut d'Estadística de Catalunya

${ }^{8}$ Encuesta de Población Activa. Instituto Nacional de Estadística

${ }^{9}$ Encuesta de Empleo del Tiempo. Instituto Nacional de Estadística. 
pues cambia la concepción de la paternidad, pero cuando se trata de cuidar personas adultas son básicamente las mujeres quienes lo hacen.

Cuarto, la escasa implicación pública. El raquitismo de las políticas familiares y de servicios de cuidado, el elevado precio de la vivienda y la precarización de las condiciones laborales agravan las tensiones en las familias y explican la dificultad de emancipación de los jóvenes, la baja natalidad, así como los problemas en la asunción de los cuidados (Adelantado y Noguera, 2000; Brullet, 2009; Comas d'Argemir, 2012).

Quinto, la independencia como valor social. Los cambios sociales y culturales en España se traducen en un creciente sentido de autonomía propia. Se incrementa el número de personas que no quieren depender de su familia en su vejez o en momentos de adversidad. Esto se explicita especialmente por parte de las personas discapacitadas, que reclaman la contribución de las políticas públicas para poder llevar una vida independiente.

Sexto, factores de clase y étnicos. Los recursos ofrecidos por el mercado empresarial no son alcanzables para la mayor parte de la población. Se expande así la contratación de empleadas del hogar como cuidadoras, buena parte de las cuales son mujeres inmigradas.

Séptimo, la presión del movimiento feminista y su participación institucional contribuyen a impulsar políticas favorables a las mujeres, que se han concretado más fácilmente durante los gobiernos socialistas. Hay que añadir también la presión de las organizaciones de personas con discapacidad reclamando políticas para la atención a su situación específica.

Octavo, hay un contexto de crecimiento económico coyuntural en España y de expansión de las políticas de bienestar que a su vez participan del estímulo de las políticas impulsadas en el espacio social europeo. Los países nórdicos iniciaron las políticas de atención a los cuidados de larga duración y en la década de los noventa les siguieron otros países, destacando el impulso conseguido en Alemania, Austria y Francia (MISSOC-Info, 1999). El problema está en que el desarrollo de estas políticas en España tiene lugar en un momento de contención y retroceso del Estado del bienestar.

A partir de estos condicionantes se construye en España un nuevo ámbito de las políticas sociales que intentan dar respuesta a las necesidades de cuidados de larga duración y que culminan con la aprobación de la denominada Ley de Dependencia en el año 2006. Cuando se habla de dependencia se atribuye a las personas adultas y no incluye la infancia. Se considera que la infancia está protegida a partir de políticas específicas y de las políticas educativas y, además, se asumen las recomendaciones emanadas de la Unión Europea respecto a la dependencia. De hecho, se utiliza la definición de dependencia del Consejo de Europa refiriéndose a las personas que por diversas razones "precisan de la atención de una u otras personas o de ayudas importantes para realizar actividades básicas de la vida diaria". La ley pretende cubrir también la "promoción de la autonomía individual", que es la expresión negociada para incluir a las personas con discapacidad en la misma ley.

El modelo de atención a la dependencia en España implica una combinación de la responsabilidad familiar, individual y social. Se trata "de un caso específico del 
régimen mediterráneo de bienestar como combinación concreta de universalismo, familismo y mercado" (Rodríguez Cabrero, 2011:18). La regulación es efectuada por el Estado, pero son las Comunidades Autónomas y los municipios quienes asumen la gestión y comparten los gastos de las aportaciones públicas.

La Ley de Dependencia tiene un objetivo ambicioso, pues según la exposición de motivos constituye una "nueva modalidad de protección social que amplía y complementa la acción protectora del Estado y del Sistema de la Seguridad Social". En el debate de la Ley se insiste en que se trata de una primera fase para la construcción de un sistema universal de servicios sociales que constituiría el "cuarto pilar del sistema de bienestar". La ley establece los servicios y prestaciones económicas que se han de garantizar, así como las condiciones de acceso en función del grado de dependencia. Marca a su vez una clara prioridad en la creación de servicios (de prevención, teleasistencia, ayuda a domicilio, centros de día y de noche y centros residenciales). En cambio, considera que las prestaciones económicas han de ser algo excepcional, reservadas para aquellos casos en que no se pueda acceder a ningún servicio público. Se prevé una aplicación progresiva de la ley, desde el año 2007 hasta el 2015, priorizando la atención de la gran dependencia hasta llegar a cubrir todos los grados. Se establece el copago de las personas usuarias, aunque la ley garantiza que quienes no tengan recursos no queden excluidos del sistema (González Ortega, Codorniu, Sáenz et al., 2010).

En octubre del 2007 se aprueba en Cataluña una nueva ley de servicios sociales en la que se especifican las directrices, la cartera de servicios y las condiciones de acceso a servicios y prestaciones ${ }^{10}$. Esta nueva ley adapta las actuaciones públicas a lo establecido por la Ley de Dependencia y añade compromisos propios desde la idea de que llegaría del Estado una inyección de recursos importante. Por primera vez se reconoce el derecho universal de los ciudadanos a acceder a servicios y prestaciones, sin depender para ello de la situación familiar, sino como un derecho individual.

Quiero destacar finalmente un aspecto que ha estado ausente en los debates relacionados con la atención a la dependencia, así como en todos los problemas relacionados en su aplicación, como es la escasa implicación de los hombres en las tareas de cuidado. Sí que esta cuestión estuvo presente cuando se impulsaron las políticas de conciliación y el permiso de paternidad, pues los hombres se han ido implicando en las tareas de crianza (Brullet, 2009), pero no lo han hecho tanto cuando se trata del cuidado de adultos. El reparto del trabajo entre mujeres y hombres se ha planteado en los foros feministas, pero ha estado ausente en el debate social y político.

\section{Las personas destinatarias de los cuidados}

\subsection{Las dependencias asociadas a la edad}

La mayor parte de situaciones de dependencia se asocian al envejecimiento, y debido a la amplitud de este fenómeno entra en las agendas políticas de los países

${ }^{10}$ Ley 12/2007, de 11 de octubre, de Servicios Sociales. Generalitat de Catalunya. 
europeos. En Cataluña la esperanza de vida al nacer en el año 2012 es de 79,78 años para los hombres y de 85,41 para las mujeres. En 1960 era de 67,4 y de 72,2 respectivamente. En poco más de cincuenta años la esperanza de vida aumenta casi 13 años, lo cual es espectacular. Esto contribuye a que aumente también el número de personas ancianas y específicamente las franjas de edad más elevadas. Y teniendo en cuenta la baja natalidad existente, también aumenta su proporción respecto al conjunto de la población.

Este envejecimiento de la población no genera en sí mismo más situaciones de dependencia, porque el aumento de la esperanza de vida ha ido acompañado de un envejecimiento sin presencia de problemas graves de salud, debido a la mejora del sistema sanitario y de la salud pública, así como de la alimentación y la calidad de vida. Así, entre los estratos con rentas altas hay una menor presencia de discapacidades asociadas a la vejez a pesar de tener una mayor proporción de personas ancianas que otras capas sociales, debido a una longevidad más elevada. Y es que el riesgo de contraer una discapacidad es inverso al gradiente de la estratificación social, y es más elevado en los estratos sociales con rentas bajas (Sarasa, 2009: 87). Por consiguiente, no se trata solo del grado de envejecimiento de la población, sino de sus condiciones de vida y de salud. Además, y para insistir en que envejecimiento no es sinónimo de dependencia, subrayaré que justamente las personas mayores son cuidadoras en proporciones crecientes, tanto por su implicación en el cuidado de los nietos y nietas, por ejemplo, como en el de otras personas adultas.

El colapso respecto a la provisión familiar de cuidados se debe fundamentalmente al cambio en las condiciones sociales y demográficas: muchas personas ancianas viven solas, la familia ha cambiado sustancialmente (los vínculos activos se han estrechado y los derivados del matrimonio son más efímeros), la mayor parte de mujeres realizan actividades laborales y los hombres apenas se implican en los cuidados de larga duración. Además, cada vez es menor la proporción de las franjas de población de edad mediana en comparación con las de más edad. Dicho de otra forma: cada vez es más frecuente que personas ancianas tengan que atender a personas que son mucho más ancianas. En Cataluña, por ejemplo, un 30\% de las cuidadoras familiares supera los 65 años.

La necesidad de cuidados de larga duración se concentra especialmente entre las personas ancianas y no sólo les afecta a ellas, sino también a sus familias y personas cuidadoras. La previsión en el crecimiento de estas necesidades constituyó un motivo esencial para la aprobación de la Ley de Dependencia, siguiendo así el modelo de otros países europeos. El Libro Blanco de atención a las personas en situación de dependencia en España hace un diagnóstico de la situación que motiva la necesidad de legislar al respecto. Detecta que las situaciones de dependencia se concentran especialmente en los hogares con rentas más bajas, que no solo han de asumir los costes económicos y de tiempo de los cuidados, sino que, además, lo han de hacer en viviendas inadecuadas para ello por problemas de espacio y de accesibilidad (Libro Blanco, 2005: 167-221). Es en estos hogares también donde las personas dependientes son cuidadas mayoritariamente por mujeres: un $72 \%$ de los casos. Y un dato significativo: un $62 \%$ de estas mujeres lleva más de cuatro años dedicada 
a cuidar, y un $41 \%$ lleva más de ocho años. Las dificultades para mantener la actividad laboral son evidentes. Sarasa (2009: 87-88) advierte que este sesgo clasista de las dependencias tiene efectos perversos sobre el riesgo de exclusión social de los hogares si la oferta de servicios públicos es insuficiente, pues las personas que dedican más de catorce horas a la semana al cuidado de una persona dependiente tienen una probabilidad elevada de perder el empleo, o de acabar haciendo trabajos marginales, lo cual repercute a su vez negativamente en el nivel de renta de estos hogares.

La inequidad social que produce la falta de servicios públicos para atender las situaciones de dependencia se refleja en el hecho de que las familias con rentas más altas pueden contratar los servicios que ofrece el mercado, tanto si se trata de residencias como si se contratan cuidadoras. En cambio, las clases sociales más bajas no lo pueden hacer y la familia asume los cuidados. Muchas de las mujeres cuidadoras son amas de casa, mayores de cincuenta años, con escasos estudios, que difícilmente serán reemplazadas cuando se dé el caso por cohortes más jóvenes y mejor formadas. Y se da la paradoja de que las familias más abnegadas en la provisión de cuidados son las "castigadas" por un sistema de servicios sociales que centra su intervención en los casos más extremos, de pobreza o abandono (Libro Blanco, 2005: 117-118). Esta inequidad social se traduce también en los costes de oportunidad de las cuidadoras: incompatibilidad laboral, efectos sobre la propia salud, y efectos sobre la vida afectiva y relacional.

La falta de servicios públicos comporta también la medicalización de la fragilidad asociada al envejecimiento y, tal como señala el Libro Blanco, hace que las familias ejerzan presión sobre los servicios de salud, por lo que se plantea que la atención a la vejez no sea un tema exclusivamente médico, que encarece la atención.

Las políticas para atender a las dependencias derivadas de la vejez debían cubrir así diversos objetivos: desmedicalizar la atención para centrarla en los problemas de salud e impulsar servicios de tipo social, incluir en el sistema público a todas las personas con necesidad de atención, dar prioridad a la atención domiciliaria y hacer posible la actividad laboral de todos los miembros del hogar.

\subsection{La especificidad de las personas con discapacidad}

En los últimos años se ha incrementado el número de personas con discapacidad reconocida, no solo porque haya habido mayor supervivencia en las enfermedades crónicas o más siniestralidad causada por accidentes de tráfico o laborales, sino también porque hay que entrar en el sistema para acceder a las ayudas públicas. Así, en Cataluña, las personas con discapacidad reconocida eran 267.988 en el año 2001 (un 4,2\% de la población) y pasan a ser 490.134 en el 2012 (un 6,5\%). De estas, 79.880 necesitan de otra persona para poder efectuar las actividades básicas de la vida diaria.

Cuando empezaron a conocerse los primeros borradores de la Ley de Dependencia, las personas con discapacidad se pusieron en alerta. Las principales organizaciones se movilizaron tanto en su dimensión reivindicativa como en su capacidad para proveer servicios. Es el caso del CERMI (Comité Español de Representantes 
de Personas con Discapacidad), de la ONCE (Organización Nacional de Ciegos Españoles), del FEAPS (Federación de Organizaciones en favor de Personas con Discapacidad Intelectual), de la Federación ECOM (Entidades Colaboradoras con el Minusválido) y de muchas otras organizaciones. Sus preocupaciones se centraban en que la ley integrara la especificidad de la atención que requerían las personas con discapacidad. Pero como entidades proveedoras de servicios querían asegurar también su presencia en el sistema.

Considero interesante el discurso que el Foro de Vida Independiente introdujo en el debate, en la medida en que agrupa a un sector de personas con discapacidad sin intereses directos en la provisión de servicios y que representa un nuevo paradigma respecto al trato recibido por las personas con discapacidad ${ }^{11}$. Reivindican que su situación no debe ser confundida con la de personas dependientes. Por el contrario, afirman que las personas con discapacidad devienen dependientes si no cuentan con las ayudas técnicas y sociales que faciliten su independencia. Por esto prefieren hablar de diversidad funcional y no de discapacidad (Romañach y Lobato, 2005). No se resignan a ser institucionalizados ni a acogerse a medidas concebidas para proteger personas con pocas opciones vitales, porque resultan claramente insuficientes para las aspiraciones de quienes reivindican la normalización de su situación en la sociedad y quienes quieren ser tratados a partir de los derechos de ciudadanía y no como personas enfermas.

El término de "mujeres y hombres con diversidad funcional" se empieza a utilizar en el año 2005, para contrarrestar la dimensión negativa que comporta el término de discapacidad y también el de minusvalía, o el de invalidez, asociados a la deficiencia, la parálisis, o el retraso, aunque, como señalan Rodríguez y Ferreira (2010: 153), no consigue de momento su plena implantación ni sustituir el modelo médico hegemónico respecto a la normalidad del cuerpo humano. En todo caso, a partir del término diversidad funcional se intenta ir más allá del modelo médico y se reivindica el pleno reconocimiento y dignidad como una expresión más de la diversidad existente en nuestras sociedades.

El Foro de Vida Independiente se movilizó a propósito de la Ley de Dependencia y también de la Ley de Servicios Sociales de Cataluña. Durante el proceso, criticó que no se diferenciase la dependencia derivada del envejecimiento de la que llega por otras causas. El Foro considera que hay que invertir los términos, pues no es que las enfermedades crónicas o la siniestralidad que afectan a las funciones del cuerpo humano causen dependencia, sino que es la dificultad de concebir los derechos sociales y la falta de políticas públicas lo que convierte a muchas personas en dependientes. Se trata, por tanto, de una situación de discriminación, que solo se puede superar si los poderes públicos ponen los medios necesarios para atender la situación específica de las personas con distintos tipos de diversidad funcional y ayudar a superar las limitaciones y restricciones en su actividad. Por ello reclaman

${ }^{11}$ El Foro de Vida Independiente es una comunidad virtual que nace a mediados del año 2001, inspirada en el Movimiento de Vida Independiente que se desarrolló en los Estados Unidos a finales de los años sesenta y constituye un espacio reivindicativo y de debate en torno a los derechos de las personas con cualquier tipo de diversidad funcional. 
un modelo específico de políticas públicas para conseguir una vida independiente. No pretenden la autonomía, que consideran un término de carácter moral sin contenido físico-práctico, sino la independencia en su actividad vital.

Su modelo de atención se inspira en la propuesta de Ratzka (2004), que inspiró a los poderes públicos de distintos países nórdicos y una de sus principales reivindicaciones es poder tener un (o una) asistente personal, que es lo que permite vivir en un hogar de forma independiente. Se rechaza el tener que vivir en residencias cuando no se quiere depender directamente de la familia. Las personas discapacitadas se han visto forzadas a la institucionalización y a no poder contar con un hogar propio por la falta de asistente personal y se reivindica con fuerza esta figura, que es quien ha de ayudar a realizar las actividades básicas de la vida diaria, acceder a los medios de transporte, al trabajo y a la educación, así como a todas las actividades de participación social. Se reivindica también que se pueda elegir a la persona asistente, y por este motivo se prefiere una prestación económica, que permite establecer las pautas y condiciones de los cuidados, más que un servicio prestado por la Administración.

Las organizaciones de personas con discapacidad consiguieron algunas modificaciones en el redactado inicial de la ley de Dependencia, aunque no todo lo que reivindicaban. Se modificó el título de la ley que, además de referirse a la dependencia, incluye también la promoción de la autonomía personal y se introdujo la figura del asistente personal en el catálogo de las prestaciones económicas.

Los objetivos de los poderes públicos eran fortalecer las acciones de prevención y conseguir que las personas con discapacidad pudieran tener autonomía propia y vivir en su propio domicilio, reservando las residencias para los grandes discapacitados. Se trataba también de que todos los miembros del hogar pudieran ejercer una actividad laboral y no verse limitados por la obligación de atender a una persona discapacitada.

\section{Los poderes públicos. El modelo de intervención pública en Cataluña}

Los servicios sociales en España se institucionalizan y adquieren entidad en el contexto democrático. Efectivamente, la dictadura franquista concebía la asistencia social como una especie de beneficencia pública que coexistía con una oferta de servicios privados, algunos de ellos provistos por entidades del tercer sector. Cuando se efectúa el paso a la democracia queda pendiente pues organizar unos servicios sociales públicos, que los partidos de izquierda conciben primordialmente vinculados al ámbito local. Pero son las Comunidades Autónomas quienes, en la construcción del nuevo sistema político, asumen las competencias en asistencia social. A pesar de ello, los ayuntamientos organizan también servicios sociales, y lo hacen tanto para atender las demandas ciudadanas como por convicción y práctica política, pues se trata de la administración de mayor proximidad, que se confronta más directamente con los problemas sociales existentes en su ámbito (Sarasa, 2000: 361-362).

La Generalitat de Cataluña, de acuerdo con su Estatuto de Autonomía, tiene las competencias en asistencia social. En la década de los años 80 se institucionalizan y definen los servicios sociales, en tensión con el mundo municipal, tanto por lo que refiere a las funciones de cada Administración como a su participación en la financiación. La Generalitat crea su propia red pública de servicios, pero lo hace 
tímidamente y, en cambio, proporciona un fuerte apoyo al sector privado. Se trata de un modelo de corte liberal, impulsado por un gobierno conservador (Convergència i Unió, CiU) que permanece en el poder de forma continuada entre 1980 y 2003, en que pasa a gobernar una coalición de izquierdas que potencia más los servicios sociales, aunque se trata de una etapa corta, pues CiU recupera nuevamente el gobierno en el $2010^{12}$. En este contexto, las políticas sociales se caracterizan por ser residuales, estar escasamente financiadas y tener un marcado carácter familista, es decir, sustentadas en la confianza de que la familia asume la tutela, supervivencia básica y adversidad de sus miembros (Adelantado y Noguera, 2000). Coherentemente, el gobierno de CiU otorga un elevado valor ideológico y moral a la institución familiar que concibe según el modelo tradicional y sitúa como piedra angular en el edificio de las políticas sociales. Jordi Pujol presidente de la Generalitat entre 1980 y 2003, insiste en diversas ocasiones en que la familia "sólida" (la formada por padre, madre e hijos, especifica) es la base del Estado del bienestar y es muy explícito al indicar que la familia es la que puede "salvar" el Estado del bienestar (Pujol, 1999).

Los programas para los cuidados de larga duración han tenido un carácter limitado y han estado asentados en el asistencialismo y en el familismo. Además, se han priorizado las prestaciones monetarias por encima de la creación de servicios. En 1988 la Generalitat crea el programa "Vida a los Años" orientado a procurar atención social a las personas ancianas necesitadas de un tratamiento médico prolongado y en 1992 crea el programa de "Acogida residencial para personas mayores", para facilitar el ingreso en residencias privadas cuando no se puede acceder a una plaza pública. En ambos casos se trata de institucionalizar a personas dependientes, pero no mediante la creación de plazas públicas, sino aportando financiación complementaria a los centros privados. Más directamente relacionados con aportes monetarios a las familias son el programa de "Apoyo a las familias con una persona mayor disminuida", creado en 1992, y el programa "Vivir en familia" que intentaba atender a un espectro más amplio de situaciones y se crea en el 2000. En estos dos últimos casos se conceden prestaciones económicas a familias con personas dependientes a su cargo. Quiero remarcar que estas prestaciones no derivaban de un derecho individual sino familiar, y que no se controlaba el uso de esta asignación económica, que en la práctica servía para incrementar la renta familiar y que frecuentemente se destinaba a pagar a alguna cuidadora doméstica. No se trataba tampoco de un derecho garantizado, ya que dependía de la disponibilidad presupuestaria y, por consiguiente, no se atendían todos los casos de necesidad, sino aquellos que el presupuesto permitía. Aunque es cierto que los presupuestos se fueron incrementando en el transcurso de los años, no alcanzaban a cubrir las necesidades existentes, que aumentaban a mayor velocidad.

El resultado de esta escasez de servicios públicos es que dejó la provisión de servicios básicos en manos del mercado, con una consecuencia clara, como es la

${ }^{12}$ Entre 2003 y 2010 gobierna la Generalitat una coalición de izquierdas formada por el Partido Socialista de Catalunya (PSC), Esquerra Republicana de Catalunya (ERC) e Iniciativa per Catalunya Verds-Esquerra Unida i Alternativa (ICV-EUiA). 
polarización que esto generó: los recursos públicos se destinaban a los más pobres; los mercantiles a los más ricos. Esta polarización, hasta hace pocos años, era muy acentuada, porque se valoraban los recursos de los componentes del entorno familiar directo (cónyuge e hijos) aunque no vivieran en el mismo hogar y, por tanto, acceder a los servicios públicos implicaba que todos los miembros de la familia tuviesen rentas muy bajas. Así, una amplia franja de población, las clases medias, no tenían ningún tipo de apoyo, porque sus rentas no eran tan bajas como para poder acceder a los servicios públicos ni eran suficientemente altas como para acceder a los privados (Adelantado y Noguera, 2000: 159-194).

Otra de las características del modelo de intervención en Cataluña es la externalización de servicios públicos hacia empresas privadas, tanto de tipo mercantil como del tercer sector. Las empresas mercantiles reciben financiación pública mediante convenios predominantemente, en tanto que las de iniciativa social lo hacen a través de subvenciones. Ambas fórmulas posibilitan el ejercicio del clientelismo en su concesión. Se trata en todo caso de un sistema de gran fragilidad, que depende de la voluntad política de cada momento y que, al mismo tiempo, convierte a las empresas mercantiles y a las entidades del tercer sector en dependientes de la financiación pública, con especial vulnerabilidad de estas últimas al estar sometidas al sistema de subvenciones, más coyuntural que los convenios.

La Ley de Dependencia y la Ley de Servicios Sociales suponen un cambio sustantivo respecto a estas políticas. La Ley de Dependencia instituye un derecho individual y universal a ser atendido. La Ley de Servicios Sociales fija este derecho como subjetivo: es decir, todas las personas evaluadas con determinados grados de dependencia tienen derecho al servicio correspondiente y, por tanto, la Administración ha de habilitar los recursos correspondientes para hacerlo efectivo. Además, la prioridad en el acceso a los servicios y el copago de los mismos se establece a partir de los recursos propios de la persona que hay que atender y no a partir de los recursos de la familia. Este factor supone ampliar considerablemente el número de personas usuarias con acceso al sistema de forma gratuita o con un copago reducido.

El impacto que supone la aprobación de estas dos leyes se visualiza muy bien en los servicios de atención domiciliaria de la ciudad de Barcelona. En el año 2004 atendieron a 10.000 personas; en el año 2010, la cifra se incrementó hasta las 63.000. Los recursos destinados a este servicio tienen también un notable incremento, pues se pasa de 10 millones de euros a 50 millones $^{13}$. Así, en tan solo seis años se multiplica por seis el número de personas beneficiarias y por cinco el presupuesto y esto se debe a que al instituirse un derecho universal y subjetivo aumenta el número de personas que se incorporan a la red de atención social. Un incremento equivalente se produce a escala regional y estatal. Así, el número de prestaciones otorgadas en Cataluña a finales del año 2008 es de 69.092 (449.415 en España); en el 2010 aumentan hasta 130.869 (800.009 en España), y en el 2012 se

${ }^{13}$ Datos del Ayuntamiento de Barcelona. 
elevan a 173.913 (959.903 en España $)^{14}$. En el cuadro 1 se presenta la distribución de las prestaciones y servicios:

\section{Cuadro 1}

Servicios y prestaciones para la atención a la dependencia. Cataluña.

1 de enero de 2012

\begin{tabular}{|l|r|l|r|}
\hline \multicolumn{2}{|l|}{ Servicios } & \multicolumn{2}{l|}{ Prestaciones económicas } \\
\hline Teleasistencia & 16.235 & Asistente personal & 21 \\
\hline Ayuda a Domicilio & 17.667 & Cuidador no profesional & 97.885 \\
\hline Centro de Día Discapacitados & 2.837 & Vinculada a Centro de Día & 199 \\
\hline Centro de Día Ancianos & 5.193 & Vinculada a Residencia & 10.425 \\
\hline Residencia-hogar & 1.015 & Vinculada a SAD & 305 \\
\hline Residencia Discapacitados & 3.271 & & \\
\hline Residencia Ancianos & 23.869 & & \\
\hline Sociosanitario & 1.410 & & \\
\hline Total servicios & 71.497 & Total prestac. económicas & \\
\hline Total prestaciones y servicios & 180.328 & & \\
\hline Total personas beneficiarias & 140.491 & & \\
\hline
\end{tabular}

Fuente: Departament de Benestar Social y Familia, Generalitat de Catalunya.

Observemos que las prestaciones económicas concedidas a inicios del 2012 (108.835) superan al número de servicios otorgados (71.497) y que el $90 \%$ de las prestaciones económicas reconocidas son para cuidadores/as no profesionales, que en la práctica implica la atención en el hogar. Tanto su bajo coste como la escasa oferta de servicios han influido en que se haya privilegiado este recurso. También ha influido la idea de que los cuidados familiares son la opción preferida y que están socialmente aceptados, lo que contribuye a reforzar la implicación de la familia y de las mujeres en la atención a la dependencia.

Más de la mitad de los servicios y prestaciones (un 50,9\%) se destinan a personas con edad superior a los 80 años, que es donde se concentra el mayor número de situaciones de dependencia. Si consideramos las personas mayores de 65 años, entonces el porcentaje se incrementa hasta el 78,1\%. El 67\% de las personas beneficiarias son mujeres, debido a su mayor longevidad. Si se relaciona las personas beneficiarias de prestaciones con el total de la población, la tasa resultante en Cataluña es de 1,83, más elevada que el promedio del conjunto de España $(1,63)$. Le superan Castilla y León $(2,43)$, Cantabria $(2,38)$, La Rioja $(2,31)$ y Andalucía $(2,29)$. Y las menos comprometidas en las políticas públicas de provisión de cuidados son la Comunidad de Madrid $(1,25)$, Baleares $(0,86)$, Comunidad Valenciana $(0,84)$ y Canarias $(0,56)$, esta

${ }^{14}$ Datos del IMSERSO, Servicios de Estadísticas de la Subdirección General Adjunta de Valoración, Calidad y Evaluación. 
última gobernada por Coalición Canaria, y las demás por el Partido Popular ${ }^{15}$. La Ley de Dependencia fue aprobada durante un gobierno socialista, y las CCAA gobernadas por el PP asumen esta ley con escaso entusiasmo e implicación.

\section{El mercado. Empresas privadas y empleadas domésticas}

En el caso de Cataluña destaca la fuerte presencia del mercado en la provisión de servicios personales, que se ha visto favorecida por la concurrencia de varios factores: el incremento de personas en situación de dependencia, la dificultad de las familias y más en concreto de las mujeres para asumir los cuidados, un cambio cultural entre las personas mayores y discapacitadas en el sentido de no querer depender de sus parientes, y la debilidad de las políticas públicas, con la creación de recursos insuficientes. La expansión del mercado se concreta en una doble dinámica: la que experimentan las empresas privadas que ofrecen servicios en el sector de los cuidados y el recurso a la contratación de cuidadoras en el hogar.

En los últimos años se experimenta un fuerte incremento de las empresas privadas, especialmente de las de iniciativa mercantil, que actúan sobre todo en el sector de las residencias, que es el que resulta más lucrativo. Tomando nuevamente como ejemplo los servicios destinados a personas mayores, mostramos en el siguiente cuadro el proceso de crecimiento de las plazas residenciales según su titularidad y en relación también a la tasa de cobertura (calculada en proporción con la población mayor de 65 años).

\section{Cuadro 2}

Servicios residenciales para personas mayores. Cataluña

\begin{tabular}{|c|c|c|c|c|c|c|c|c|}
\hline \multirow[b]{2}{*}{ Titularidad } & \multicolumn{2}{|l|}{$1996^{1}$} & \multicolumn{2}{|l|}{2001} & \multicolumn{2}{|l|}{2006} & \multicolumn{2}{|l|}{2011} \\
\hline & Plazas & $\%$ & Plazas & $\%$ & Plazas & $\%$ & Plazas & $\%$ \\
\hline $\begin{array}{l}\text { Pública directa } \\
\text { Generalitat } \\
\text { Administración local }\end{array}$ & 6.427 & 20,3 & $\begin{array}{l}6.261 \\
3.500 \\
2.761\end{array}$ & 16,02 & $\begin{array}{l}8.195 \\
4.720 \\
3.475\end{array}$ & 17,76 & $\begin{array}{l}9.178 \\
4.662 \\
4.516\end{array}$ & 16,38 \\
\hline $\begin{array}{l}\text { Privada con financiación pública } \\
\text { Iniciativa mercantil } \\
\text { Iniciativa social }\end{array}$ & 1.219 & 3,85 & $\begin{array}{l}898 \\
568 \\
330\end{array}$ & 2,30 & $\begin{array}{l}9.787 \\
6.862 \\
2.925\end{array}$ & 20,00 & $\begin{array}{r}19.786 \\
14.269 \\
5.517\end{array}$ & 35,32 \\
\hline $\begin{array}{l}\text { Privada } \\
\text { Iniciativa mercantil } \\
\text { Iniciativa social }\end{array}$ & 24.007 & 75,85 & $\begin{array}{r}31.912 \\
17.433 \\
9.674\end{array}$ & 81,68 & $\begin{array}{r}30.928 \\
21.272 \\
9.656\end{array}$ & 63,24 & $\begin{array}{r}27.059 \\
19.307 \\
7.752\end{array}$ & 48,40 \\
\hline Total & 31.653 & 100,00 & 39.071 & 100,00 & 48.907 & 100,00 & 56.023 & 100,00 \\
\hline Tasa de cobertura & & 3,19 & & 3,54 & & 4,25 & & 4,42 \\
\hline
\end{tabular}

Fuente: Mapa de Serveis Socials de Catalunya. Departament de Benestar Social i Familia, Generalitat de Catalunya. Elaboración propia.

${ }^{15}$ Datos a 1 de diciembre de 2012. Fuente: IMSERSO, Ministerio de Sanidad, Servicios Sociales e Igualdad, Gobierno de España. 
Podemos comprobar en el cuadro 2 el fuerte incremento, entre 1996 y 2011, de plazas residenciales, que pasan de 31.653 a 56.023. Pero lo que destaca es que en todo el proceso se mantiene el fuerte predominio del sistema privado. Generalitat y ayuntamientos implantan nuevos servicios públicos, pero la oferta pública más reciente se asienta fundamentalmente en la externalización de los servicios residenciales hacia empresas privadas, especialmente las de iniciativa mercantil. El ritmo se mantiene constante hasta que en el 2003 entra un gobierno de izquierdas en la Generalitat y establece como prioridad potenciar el sistema público. De ahí que, como podemos ver en el cuadro 2, en el 2006 hay un fuerte incremento de la oferta pública, que alcanza el $37,76 \%$ de las plazas residenciales, tanto porque se crean nuevas plazas de titularidad pública (que representan el 17,76\% del total) como porque se integran en el sistema público numerosas plazas privadas (que en el 2001 representaban sólo un 2,30\% del total y pasan a un $20 \%$ en el 2006).

Pero el gran salto se produce con la aplicación de la Ley de Dependencia y la Ley de Servicios Sociales que incrementa el número de personas a ser atendidas en el sistema y lo colapsa. Esto se traduce en un crecimiento exponencial de las plazas privadas que reciben financiación pública, que entre 2006 y 2011 doblan en número (de 9.787 a 19.786) y llegan a representar un $35,32 \%$ de las plazas. Destaca también la congelación en el número de plazas de titularidad pública de la Generalitat, que contrasta con el dinamismo de los ayuntamientos. Así, en el 2011, la oferta pública de plazas residenciales públicas alcanza por primera vez más de la mitad de la oferta existente (un 51,70\%), pero la mayor parte de ellas resultan de una externalización hacia servicios privados. Esto permite una mayor flexibilidad a la Administración, que evita incrementar la dimensión del sector público y financia el sistema privado en función de las demandas existentes pero también de las disponibilidades presupuestarias. Los recortes en la aplicación de la Ley de Dependencia están suponiendo justamente una disminución de este tipo de externalización.

Lo interesante a destacar de estos datos es que la asunción de responsabilidad pública en el tema de los cuidados no tiene como consecuencia un retroceso del mercado, sino que por el contrario, lo potencia. La expansión del mercado es efectivamente muy importante: un 79,70\% de las plazas residenciales en 1996; un $83,62 \%$ en 2011, muchas de ellas financiadas con dinero público. Esto se explica básicamente por la dificultad de la Administración de generar en poco tiempo todos los dispositivos asistenciales que requieren los nuevos derechos reconocidos por las leyes, a la importante presencia del tercer sector social en la provisión de servicios en coordinación con la familia, y a la propia naturaleza de los cuidados, que inciden en el ámbito íntimo y propicia la libertad de elección (Rodríguez Cabrero, 2011: 16).

Una consecuencia de esta expansión del mercado es la inadecuación entre la oferta y la demanda, porque la iniciativa privada se concentra especialmente en el sector de las residencias y no tanto en servicios domiciliarios, centros de día o viviendas asistidas, que generan menos beneficios. Sin embargo, las personas que deben ser atendidas prefieren de forma bastante generalizada permanecer en el propio hogar y no ser institucionalizadas en una residencia. Este factor, junto con el elevado coste de las plazas residenciales, propicia la contratación de cuidadoras en el hogar. 
La contratación de cuidadoras ha sido y sigue siendo un recurso muy utilizado, pues permite comprar servicios a bajo coste, frecuentemente suministrados por mujeres inmigradas, sea mediante contratos legales sea en el contexto de la economía sumergida (Comas d'Argemir, 2009; Parella, 2003). La cuidadora doméstica constituye una alternativa percibida como una continuidad de lo que tradicionalmente se hace en el hogar, más parecida al ideal de familia cuidadora y preferida a la institucionalización; sustituye a las mujeres de la familia, y se le supone capaz de entrega y afecto al tiempo que realiza su labor (Comas d'Argemir y Roca, 1996; Waernes, 2001). Es también una alternativa más barata que las otras que ofrece el mercado y a veces la única asequible.

Entre las cuidadoras domésticas predominan en Cataluña las mujeres latinoamericanas, especialmente ecuatorianas, peruanas, bolivianas y colombianas. Influyen factores muy diversos, tanto desde el punto de vista de la oferta como de la demanda. En el caso de las mujeres inmigradas influyen los proyectos migratorios, las redes relacionales, así como las concepciones culturales sobre trabajo y género. También las políticas de extranjería, pues el servicio doméstico ha sido prácticamente la única opción de las mujeres para entrar legalmente en España y es también prácticamente la única opción de tener trabajo si se encuentran en situación irregular. A diferencia de las empleadas domésticas de origen español, que suelen ser mayores y con escaso nivel de estudios, muchas mujeres latinoamericanas tienen estudios secundarios e incluso superiores. Por lo que respecta a empleadores, las cuestiones lingüísticas, pero también los estereotipos étnicos influyen en sus preferencias. Puesto que se trata de prestar cuidados, se valora el trato, la capacidad de empatía, la suavidad y dulzura, la conversación, junto con determinada experiencia de la actividad. Se constituye así una relación basada en la ambigüedad afectiva. Hay que estar disponible y ser a la vez invisible, siendo esta invisibilidad que se espera de las mujeres migrantes cuidadoras un aspecto asociado a su vulnerabilidad (Gorban, 2012; Roca, 2009: 162).

Las dimensiones de género, clase y etnia quedan nítidamente expresadas en este tipo de relación laboral. El género, por las capacidades que se atribuyen a las mujeres en torno a los cuidados y la falta de implicación de los hombres. La mercantilización de esta actividad no modifica los patrones de género, sino que se asienta en ellos: finalmente son cosas que se arreglan entre mujeres y que evitan las tensiones de reestructurar o cuestionar los roles de género en el hogar. La desigualdad de clase se expresa en la asimetría entre las personas empleadoras y las empleadas y en la vulnerabilidad de las mujeres que no tienen su situación regularizada. El tipo de régimen laboral existente en España para las empleadas del hogar, con escasos derechos laborales y baja remuneración, ha propiciado que este sector haya sido ocupado por migrantes (Anderson, 2012; Le Feuvre, Ervik, Krajewska et al., 2012; Simonazzi, 2008). La dimensión étnica se cruza con la de clase y se expresa en lo que Ehrenreich y Hochschild (2002) denominan "cadenas globales de cuidados", o en lo que Colen (1995) denomina "reproducción estratificada", ambas fruto de la relación desigual entre países. Este que este tipo de migraciones femeninas produce una desestabilización estructural de los países de origen, al provocar una crisis en 
los modelos de género, y en concreto en la masculinidad, así como una alteración en los patrones de parentesco (Bodoque y Soronellas, 2010; Gregorio, 1998; Martín, 2008; Parella, 2003; Soronellas, 2010).

\section{La Ley de Dependencia, un trayecto frustrado nada más empezar}

A principios del año 2007 entra en vigor la Ley de Dependencia y las administraciones públicas se ven inmediatamente desbordadas. El colapso se produce especialmente en los servicios de valoración que han de reconocer la dependencia y determinar su grado. Se llega a esperar hasta dos años para obtener este reconocimiento, que es requisito imprescindible para poder acceder a las prestaciones y servicios previstos por la ley. También hay problemas en la asignación de servicios, pues no se cuenta con los suficientes para atender a todas las necesidades. Pero a pesar de retrasos y dificultades, y a pesar también de la crisis económica, se va produciendo una incorporación progresiva de personas al sistema, que se mantiene hasta el año 2011.

Inmediatamente se ponen de manifiesto también los problemas derivados de la financiación, que en parte son estructurales y en parte derivados de la crisis económica y de las políticas de austeridad. Se produce por ejemplo un desfase entre las previsiones iniciales y la realidad, que las supera, tanto por el número de personas beneficiarias y solicitantes, como por las afectadas por una gran dependencia, que tienen mayores costes.

Además, ya desde el inicio, las aportaciones públicas previstas sufren retrasos, lo que entorpece el proceso y genera problemas a ayuntamientos y Comunidades Autónomas, que son quienes prestan los servicios. Sánchez Maldonado (2010), que hace un análisis riguroso de la aplicación de la ley con datos del año 2009, muestra como el principio de que el Estado y las Comunidades Autónomas deberían hacer aportaciones equivalente se trunca en perjuicio de las últimas, porque la mitad del coste mínimo garantizado que aporta el Estado resulta ser inferior a la mitad de lo que realmente cuestan las prestaciones, y porque las Comunidades Autónomas, además, han de incrementar necesariamente su carga presupuestaria a medida que entran nuevas personas usuarias en el sistema sin que la financiación básica del Estado aumente. De hecho la Ley de Dependencia recoge un redactado favorable al Estado, ya que obliga a las Comunidades Autónomas a igualar la aportación del Estado, pero no al revés.

En el caso de Cataluña esto comporta una situación dramática para las arcas de la Generalitat: las aportaciones del Estado se reducen año a año, en términos absolutos y también relativos, lo cual obliga a la Generalitat a hacer un sobreesfuerzo económico para cubrir las necesidades existentes. Así, en el año 2009, el Estado aportó 322,67 millones de euros (un 37,2\% de la financiación de las prestaciones) y la Generalitat 544,69 (un 62,8\%). En el 2011 la aportación del Estado se redujo a 258,44 millones (un 22,2\% de la financiación). En 2013 la desproporción fue aún mayor, como fruto de la reforma aprobada en julio de 2012, a la que me referiré más adelante. El Estado aporta solo 192,22 millones de euros, y la Generalitat 1.335,32 millones: un $12,6 \%$ y un $87,4 \%$ respectivamente. 
Como consecuencia de esta suma de problemas, las Comunidades Autónomas tienden a conceder más prestaciones económicas que servicios, pues son menos costosas tanto monetariamente como en gestión y más rápidas de solucionar. Lo que la Ley de Dependencia contemplaba como una excepción se convierte pues en la opción mayoritaria. En Cataluña, por ejemplo, se destinan en el año 2009, 45 millones de euros a servicios y 76,8 millones a prestaciones económicas, de manera que por cada euro que se destina a servicios, se destina 1,7 a prestaciones (Sánchez Maldonado, 2010: 75). Y esto redunda lógicamente, en la escasez de servicios, que la Administración intenta cubrir, tal como hemos visto anteriormente, comprándolos al mercado. Y entre las prestaciones económicas, una abrumadora mayoría (el 90\%) se destina al pago de personas cuidadoras en el entorno familiar ${ }^{16}$. Retengamos este dato, porque tiene especial importancia para valorar las actuaciones políticas recientes.

La Ley de Dependencia empieza a implementarse en el año 2007, y a pesar de la crisis económica, el sistema se va desplegando hasta finales del 2011, en que el gobierno reduce los presupuestos y pospone la atención de las personas con dependencia moderada ${ }^{17}$. En el Programa Nacional de Reformas (2012: 105-106) que España presentó a la Comisión Europea se anuncian las medidas de mayor calado en la reforma de la Ley: la revisión del calendario y nivel de aplicación del sistema para acompasarlo a las capacidades financieras, la revisión de las cuantías y condiciones destinadas a los y las cuidadoras no profesionales (familiares), el incremento de las aportaciones de las personas usuarias (el copago) y la potenciación del sector privado. Y, efectivamente, estos objetivos guían las reformas que se efectúan en 2012, algunas de las cuales tienen un mero componente técnico, pero otras, en cambio, suponen una fuerte afectación al sistema, que repercute en las personas con dependencia, refamiliariza las actividades de cuidado y resta responsabilidad al sector público en favor de los intereses del mercado. La reforma es una expresión de unos determinados intereses de clase y da por supuesto que las mujeres harán igualmente de cuidadoras con o sin remuneración, y en todo caso disminuyendo sus derechos ${ }^{18}$.

La reforma del 2012 supone ya de entrada una disminución de personas beneficiarias del sistema de atención a la dependencia, que en junio de 2013 se reducen a 939.642 (20.251 menos que un año antes). Y el hecho de aplazar hasta el año 2015

${ }^{16}$ Las preferencias de las cuidadoras han dado un vuelco, pues en 1994 se inclinaban por recibir prestaciones económicas (un 61,5\%), y en 2004, en cambio, muestran mayor preferencia por recibir apoyo de los poderes públicos en forma de servicios, especialmente ayuda a domicilio, según indica el Libro Blanco, 2005, p. 218.

${ }^{17}$ Real Decreto-Ley 20/2011, de 30 de diciembre, de medidas urgentes en materia presupuestaria, tributaria y financiera para la corrección del déficit público.

${ }^{18}$ Estas reformas se concretan en la Resolución de 13 de julio de 2012, de la Secretaría de Estado de Servicios Sociales e Igualdad por la que se publica el Acuerdo del Consejo Territorial del Sistema para la Autonomía y Atención a la Dependencia para la mejora del sistema para la autonomía y atención a la dependencia. Las dimensiones económicas se establecen en el Real Decreto-ley, de 13 de julio, de medidas para garantizar la estabilidad presupuestaria y el fomento de la competitividad. 
la incorporación de personas al sistema de atención a la dependencia deja sin ayuda a más de 150.000 dependientes leves, lo cual afecta especialmente a los sectores con ingresos más bajos, que es donde se concentran especialmente las situaciones de dependencia. Y a ello hay que sumar los efectos de una importante reducción presupuestaria. Volvamos a la situación de Cataluña para ver cómo se concretan. Hemos citado ya la fuerte disminución de las aportaciones del Estado, lo cual supone en la práctica un desmantelamiento de los compromisos establecidos por la ley. Así, a pesar del incremento constante del presupuesto de la Generalitat, no llegan a cubrirse las necesidades existentes y los efectos de ello son como una bola de nieve. En julio del 2013, la Generalitat decide suspender la prestación de ayudas para acceder a residencias privadas (las plazas concertadas), lo que incrementa las listas de espera para acceder a una plaza pública. También aumenta el copago, es decir, las aportaciones de los usuarios y el número de perceptores de prestaciones disminuye. Si a ello añadimos que cuando escribía este texto estaba pendiente de una nueva reforma por parte del Estado orientada a incrementar todavía más los aportes de las personas usuarias, podemos deducir que se está retrocediendo hacia la situación previa a la aprobación de la ley de Dependencia en que servicios y prestaciones tenían un carácter puramente asistencialista. Los servicios sociales universales se alejan cada vez más del horizonte; el cuarto pilar del Estado del bienestar se resquebraja profundamente.

Quiero detenerme en los denominados 'cuidadores no profesionales'. Datos del 2010 en Cataluña muestran que mayoritariamente se trata de mujeres (un 76\%), predominantemente de edades avanzadas (un 30\% superan los 65 años; y el 56\% tiene entre 46 y 64 años), y fuerte presencia de hijos o hijas (un 51\%) ${ }^{19}$. Estas cuidadoras no profesionales recibían una asignación económica cuyo importe se graduaba de acuerdo con el grado de dependencia de la persona beneficiaria ${ }^{20}$. Se trataba de una asignación baja que con la reforma del 2012 se reduce en un 15\% (oscila entre los 442,59 euros para la gran dependencia y los 153 euros para la menor). Además, estas cuidadoras tenían que darse de alta como trabajadoras en el Sistema de la Seguridad Social (excepto las que ya lo estaban o cobraban una pensión de jubilación) y el Estado asumía los gastos de la cotización. Con la reforma se restringe esta posibilidad y la limita a las cuidadoras familiares que ya estuvieran conviviendo con la persona afectada por dependencia un año antes de solicitar la prestación, lo que elimina la posibilidad de utilizar la prestación para contratar una cuidadora en el hogar. Además, el Estado deja de pagar la cotización. El resultado de esta medida ha sido la expulsión del sistema de la Seguridad Social de la mayor parte de cuidadoras que se habían acogido a él, porque la realidad social es que muchas personas con dependencias leves viven solas, lo que no impide ser atendidas por algún familiar $\mathrm{y}$, en casos más graves, puede que hayan pasado a convivir en un mismo hogar sin que ello haya supuesto necesariamente modificar su empadronamiento. El caso es que

${ }^{19}$ Datos del Departament d'Acció Social i Ciutadania, Generalitat de Catalunya.

${ }^{20} \mathrm{El}$ pago de estas asignaciones a cuidadores no profesionales disuelve las fronteras entre cuidado formal e informal. Ungerson (1995) discute las consecuencias de este tipo de prestaciones en términos de género. 
en julio del 2012 había en España 179.829 cuidadoras dadas de alta a la Seguridad Social y en junio del 2013 se reducen a $19.054^{21}$. La disminución es drástica. La reducción de costes para el Estado se hace a costa de la refamiliarización del cuidado y de que las mujeres ocupen el lugar de las políticas sociales, porque las personas que tenían necesidad de ser atendidas no dejan de tener esta necesidad.

Las políticas públicas de atención a los cuidados de larga duración han sido un complemento de lo que hace la familia en las tareas de cuidado, pero no ha modificado la división sexual del trabajo. Más todavía, las prestaciones económicas, asignadas mayoritariamente a mujeres, han tendido a reforzar su papel como cuidadoras, tanto si han servido para pagar directamente a un miembro de la familia como para contratar a una cuidadora. Recordemos que se trataba de una medida excepcional y que, en cambio, resulta ser la más difundida y a la que se destinan más recursos.

En todo caso, la regresión de las políticas sociales y, más en concreto de las relacionadas con los cuidados de larga duración, hacen que las mujeres reemplacen los servicios públicos haciéndose cargo del trabajo no pagado. Otra de las consecuencias es la quiebra de muchas entidades del Tercer Sector Social, perjudicadas por el retraso en el pago de subvenciones y la disminución de las mismas. Y se está produciendo también un incremento de la beneficencia: el Banco de Alimentos, un nuevo Banco de Medicamentos, comedores organizados por grupos de vecinos y vecinas, o entidades que intentan paliar la situación de las personas más vulnerables. De esta forma, la caridad sustituye los derechos sociales, en un itinerario que revierte los avances sociales que se habían conquistado. Lo que había adquirido visibilidad y racionalidad está volviendo al mundo oculto de lo privado, la moralidad y los afectos.

\section{Conclusiones}

El cuidado es esencial para la sostenibilidad de la vida y la reproducción social. Las políticas de provisión pública de cuidados dan visibilidad a estas actividades y a su valor social y económico. No tener en cuenta la importancia de las actividades de cuidado, comporta exacerbar las desigualdades de género y por tanto restar a las mujeres derechos de ciudadanía. No tener en cuenta el principio de la reciprocidad generacional hace que las personas que requieren apoyo y asistencia sean tratadas como meros objetos de cuidado que generan problemas y gastos, y no como ciudadanos.

Las políticas de provisión de cuidados se han de contemplar desde una perspectiva holística y transversal (Lewis, 2007: 271). Fortalecer alguna de sus dimensiones, sin atender las otras, puede conducir a unos resultados que se aparten de los objetivos que se quieren conseguir. Son políticas para proporcionar tiempo, para proveer servicios y para asignar prestaciones económicas. Cada una de estas políticas, y las tres al mismo tiempo, son necesarias porque en su conjunto son las que hacen posible un reparto equilibrado de las responsabilidades de cuidar y también una atención satisfactoria. Hemos podido comprobar que las políticas de atención a

${ }^{21}$ Según datos del Ministerio de Empleo y de la Seguridad Social. 
la dependencia se han centrado en una dimensión muy restrictiva de los cuidados, los de larga duración, lo que oculta que las personas deben recibir cuidados en diferentes momentos de la vida así como la amplia variedad de situaciones existentes.

Hemos mostrado en este artículo cómo las políticas para atender los cuidados de larga duración se han asentado en el familismo y en el trabajo de las mujeres, lo que en el caso de Cataluña suponen una continuidad respecto al abordaje que los poderes públicos habían dado a estas situaciones. Los empleos generados por las necesidades de los cuidados de larga duración están fuertemente feminizados, y cuando se trata de ejercerlos de forma no remunerada en el hogar son las mujeres quienes los ejercen predominantemente. El hecho de que la aplicación de la Ley de Dependencia haya comportado priorizar las prestaciones económicas por encima de los servicios no modifica esta situación estructural, pues lo que cambió es que algunas cuidadoras familiares pasaran a recibir una remuneración cuando antes no la tenían. La crisis económica y las restricciones presupuestarias hacen que se vuelva a la situación previa: las necesidades de cuidado no dejan de existir y, por tanto, el hecho de que los poderes públicos declinen sus responsabilidades respecto al cuidado, implica que este se reprivatiza en el seno de los hogares y afecta especialmente la carga de trabajo de las mujeres. Nada de esto es explícito, sino que se trata de situaciones de hecho, asentadas en la naturalización del trabajo reproductivo asignado a las mujeres. Ni los poderes públicos lo mencionan como tal, ni los recortes y cambios en la Ley de Dependencia han generado grandes protestas sociales. La conclusión es que no se ha avanzado en la universalización de servicios sociales $\mathrm{y}$, por tanto, este cuarto pilar del estado del bienestar no ha llegado a tener una base firme que permitiera consolidar derechos, y esto no se debe sólo a la crisis económica sino a la fragilidad misma del modelo que se construyó.

Otro de los rasgos que caracteriza a la forma en que la Ley de Dependencia se ha implantado en Cataluña es que la implicación pública ha ido acompañada de una fuerte expansión de los servicios suministrados por el mercado. Esto se debe a distintas razones: el predominio de gobiernos conservadores que basan su gestión pública en la potenciación del sector privado, la prioridad de las prestaciones económicas por encima de los servicios, que también se vincula a la necesidad de dar respuesta al rápido incremento de personas usuarias y a las preferencias de estas de ser atendidas en el hogar y no institucionalizadas. Estas prestaciones han contribuido a su vez a potenciar la contratación de cuidadoras en el hogar. El régimen laboral existente en España y las propias políticas de extranjería han propiciado que este sector haya sido ocupado por mujeres inmigradas, con bajos salarios y precarias condiciones laborales. Las desigualdades de clase y étnicas se expresan en este tipo de mercantilización del cuidado.

Las políticas de atención a los cuidados de larga duración no han alterado la división sexual del trabajo ni tampoco los componentes de clase en la organización del trabajo reproductivo. Efectivamente, persiste una estructura de género que vincula a las mujeres al cuidado, y no se ha producido una implicación equitativa de los hombres en este tipo de trabajo. El papel de mujeres y hombres no es algo naturalizado e inamovible, sino fruto del pacto social en la distribución del trabajo entre 
los sexos y fruto de decisiones políticas. Las políticas de atención a los cuidados de larga duración, tal como han sido aplicadas, han tenido a reforzar el papel de las mujeres como cuidadoras, a mantener el reparto desigual del cuidado entre hombres y mujeres y a reproducir las estructuras de desigualdad. Y esta es la otra conclusión: la persistencia de la inequidad social. Y es que los estratos sociales más bajos no pueden recurrir al mercado para externalizar o complementar las actividades de cuidado. Son las clases medias o altas quienes lo pueden hacer, evitando cuestionar la estructura de género en el la familia y delegando en terceras personas lo que en el hogar harían las mujeres. Y es que la conducta de género es también un acto de clase.

\section{Referencias bibliográficas}

ADELANTADO, José; NOGUERA, José Antonio.

2000 "Polítiques de serveis socials i rendes mínimes d'inserció: les assignatures pendents de la ciutadania social", en R. Gomà, J. Subirats (Coords.), Govern i polítiques públiques a Catalunya (1980-2000). Autonomia i benestar. Barcelona: Ed. Universitat de Barcelona, 159-194.

ANDERSON, Bridget.

2012 "¿Quién los necesita? Trabajo de cuidados, migración y política pública", Cuadernos de Relaciones Laborales, 30(1): 45-61. URL: <http://revistas.ucm.es/ index.php/CRLA/article/view/39113>, acceso 7 de marzo de 2014.

BODOQUE, Yolanda; SORONELLAS, Montserrat.

2010 "Parejas en el espacio transnacional: los proyectos de mujeres que emigran por motivos conyugales". Migraciones Internacionales, 5(3): 14-174. URL: <http://www. scielo.org.mx/scielo.php?script=sci_arttext\&pid=S1665-89062010000100005>, acceso 7 de marzo de 2014.

BRULLET, Cristina (Coord.).

2009 Temps i cura. La coresponsabilitat social de la cura a la vida quotidiana. Barcelona: Generalitat de Catalunya, Departament d'Acció Social i Ciutadania. URL: <http:// www20.gencat.cat/docs/dasc/01Departament/08Publicacions/Ambits\%20tematics/ Families/01 tempscura09/2009tempsicura.pdf.pdf> , acceso 27 de febrero de 2014.

CARRASCO, Cristina; BORDERÍAS, Cristina; TORNS, Teresa.

2011 "El trabajo de cuidados: antecedentes históricos y debates actuales", en C. Carrasco, C. Borderías, T. Torns (Eds.), El trabajo de cuidados. Historia, teoría y políticas. Madrid: Catarata, 13-97.

CARRASCO, Cristina; BORDERÍAS, Cristina; TORNS, Teresa (Eds.).

2011 El trabajo de cuidados. Historia, teoría y políticas. Madrid: Catarata.

CERRI, Chiara; ALAMILLO-MARTÍNEZ, Laura.

2012 "La organización de los cuidados, más allá de la dicotomía entre esfera pública y esfera privada". Gazeta de Antropología, 28(2), artículo 14. URL: <http://www. gazeta-antropologia.es/?p=4145>, acceso 7 de marzo de 2014 . 
COLEN, Shelee.

1995 "Like a Mother to Them': Stratified Reproduction and West Indian Childcare Workers and Employers in New York", en F.D. Ginsburg, R. Rapp (Eds.), Conceiving the New Order. The Global Politics of Reproduction. Berkeley: University of California Press, 78-102

COMAS D'ARGEMIR, Dolors.

1994 "Gender Relations and Social Change in Europe: On Support and Care", en V.A. Goddard, Llobera, J.R. y C. Shore (Eds.), The Anthropology of Europe. Oxford: Berg, 209-225.

1995 Trabajo, género y cultura. La construcción de desigualdades entre hombres y mujeres. Barcelona: Icaria.

2000 "Mujeres, familia y Estado del bienestar", en T. del Valle (Ed.), Perspectivas feministas desde la antropología. Barcelona: Ariel, 187-204.

2009 "Economía sumergida, género e inmigración. La atención a la dependencia", en A. Téllez-Infantes, J.E. Martínez-Guirao (Eds.), Economía informal y perspectiva de género en contextos de trabajo, Barcelona: Icaria, 169-196.

2012 "Políticas públicas y vida cotidiana. Redescubrimiento y auge de las políticas familiares en España", Scripta Nova. Revista electrónica de Geografía y Ciencias Sociales. Barcelona: Universidad de Barcelona, 15 de marzo de 2012, vol. XVI, nº 395 (20). URL: <http://www.ub.es/geocrit/sn/sn-395/sn-395-20.htm>, acceso 7 de marzo de 2014.

COMAS D'ARGEMIR, Dolors; ROCA, Jordi.

1996 "El cuidado y la asistencia como ámbito de expresión de la tensión entre biología y cultura", en J. Contreras (Coord.), Reciprocidad, cooperación y organización comunal. Desde Costa hasta nuestros días. Zaragoza: VII Congreso de Antropología, 57-70.

DURÁN, María Ángeles (Dir.).

1988 De puertas adentro. Madrid: Instituto de la Mujer: Ministerio de Cultura.

EHRENREICH, Barbara; HOCHSCHILD, Arlie R. (Eds.).

2002 Global Woman. Nannies, Maids and Sex Workers in the New Economy. Nueva York: Henry Holt and C.

ESTEBAN, Mari Luz.

2011 Crítica del pensamiento amoroso. Barcelona: Bellaterra.

EZQUERRA, Sandra.

2011 "Crisis de los cuidados y crisis sistémica: la reproducción como pilar de la economía llamada real”. Investigaciones Feministas, 2: 175-194. Doi: http://dx.doi. org/10.5209/rev_INFE.2011.v2.38610

FINCH, Janet.

1989 Family Obligations and Social Change. Cambridge: Polity Press.

FINEMAN, M. A.

2000 "Cracking the Foundational Myths: Independence, Auttonomy, and SelfSufficiency." Journal of Gender, Social Policy and the Law, 8: 13-29. 
URL: <http://heinonline.org/HOL/LandingPage?handle=hein.journals/ ajgsp8\&div=8\&id=\&page $=>$, acceso 7 de marzo de 2014 .

2004 The Authonomy Myth. A Theory of Dependency. New York: The New Press.

FRANZÉ, Adela.

2013 "Perspectivas antropológicas y etnográficas de las políticas públicas”. Revista de Antropología Social, 22: 9-23. URL: <http://revistas.ucm.es/index.php/RASO/article/view/43771/41354>, acceso 7 de marzo de 2014.

GLEDHILL, John.

1999 El poder y sus disfraces. Perspectivas antropológicas de la política. Barcelona: Bellaterra.

GONZÁLEZ ORTEGA, Santiago; CODORNIU, Julia; SÀENZ, Eva; et al.

2010 Informe sobre la Ley de Promoción de la Autonomía Personal y Atención a las personas en situación de dependencia. Barcelona: Fundación Democracia y Gobierno Local. Diputación de Barcelona. URL: <http://repositorio.gobiernolocal.es/xmlui/ handle/10873/685>, acceso 27 de febrero de 2014.

GORBAN, Débora.

2012 "Empleadas y empleadoras. Tensiones de una relación atravesada por la ambigüedad”. Revista Española de Investigaciones Sociológicas, 140: 29-48. Doi: http:// dx.doi.org/10.7440/res45.2013.06

GREGORIO, Carmen.

1998 Migración femenina. Su impacto en las relaciones de género. Madrid. Narcea.

HARRIS, Olivia; YOUNG, Kate.

1981 "Engendered structures: some problems in the analysis of reproduction", en J. Kahn; J. R. Llobera (Eds.), The Anthropology of Pre-capitalist Societies. London: Macmillan, 109-147.

LE FEUVRE, Nicky; ERVIK, Rune; KRAJEWSKA, Anna et al

2012 "Remaking Economic Citizenship in Multicultural Europe: Women's Movement Claims and the 'Commodification of Elderly Care", en B. Halsaa, S. Roseneil, S. Sümer (Eds.), Remaking Citizenship in Multicultural Europe. Women's Movements, Gender and Diversity. Hampshire: Palgrave and Macmillan, 70-93. Doi: http:// dx.doi.org/10.1057/9781137272157.0008

LEWIS, Janet.

2007 "Gender, Ageing and the 'New Social Settlement'. The Importance of Developing a Holistic Approach to Care Policies”. Current Sociology, 55(2): 271-286. Doi: http:// dx.doi.org/10.1177/0011392107073314

Libro blanco. Atención a las personas en situación de dependencia en España. 2004.

2005 Madrid: IMSERSO, Ministerio de Trabajo y Asuntos Sociales.

MANDELL, Betty R. (Ed)

2010 The Crisis of Caregiving. Social Welfare Policy in the United States. New York: Palgrave Macmillan. Doi: http://dx.doi.org/10.1057/9780230107847 
MARTÍN, Emma.

2008 "El impacto del género en las migraciones de la globalización: mujeres, trabajos y relaciones interculturales", Scripta Nova. Revista Electrónica de Geografía y Ciencias Sociales, XIII (270) (en línea). http://www.ub.es/geocrit/sn/sn-270-133. htm, acceso 27 de febrero de 2014.

MISSOC-Info.

1999 "Les soins de longue durée". Bulletin du système d'information mutuelle sur la protection sociale dans l'Union européenne, 1/99.

PARELLA, Sonia.

2003 Mujer, inmigrante y trabajadora: la triple discriminación. Barcelona: Anthropos.

PÉREZ OROZCO, Amaia.

2006 "Amenaza tormenta: la crisis de los cuidados y la reorganización del sistema económico". Revista de Economía Crítica, 5: 7-37. URL: <http://revistaeconomiacritica. org/sites/default/files/revistas/n5/1_amenaza_tormenta.pdf $>$, acceso 7 de marzo de 2014.

PETERSON, Elin.

2007 "El género en los marcos interpretativos sobre la 'conciliación de la vida familiar y laboral”, en M. Bustelo, E. Lombardo (Eds.), Políticas de igualdad en España y en Europa. Madrid: Cátedra, 37-66.

Programa Nacional de Reformas.

2012 Reino de España. URL: <http://www.empleo.gob.es/es/sec_trabajo/debes_saber/ pnr/120504_PNR_ESPANYA_2012-1.pdf>, acceso 7 de marzo de 2014.

PUJOL, Jordi.

1999 Créixer en Benestar. Barcelona: Generalitat de Catalunya.

RATZKA, Adolf (Ed.).

2004 "Model Nacional Personal Assistance Policy", A Project of The European Center forExcellence in Personal Assistance (ECEPA). URL: <http://www.independentliving.org/docs6/ratzka200410a.pdf>, acceso 27 de febrero de 2014.

ROCA, Jordi.

2009 "Reproducir la reproducción: mujeres migrantes y economía informal”, en A. Téllez, J.E. Martínez (Eds.), Economía informal y perspectiva de género en contextos de trabajo. Barcelona: Icaria, 153-168.

RODRÍGUEZ DÍAZ, Susana, FERREIRA, Miguel A.V.

2010 "Diversidad funcional: Sobre lo normal y lo patológico en torno a la condición social de la dis-capacidad",. Cuadernos de Relaciones Laborales, 28 (1): 151-172. URL: $<$ http://revistas.ucm.es/index.php/CRLA/article/view/CRLA1010120151A/32218 >, acceso 7 de marzo 2014.

RODRÍGUEZ CABRERO, Gregorio.

2011 "Políticas sociales de atención a la dependencia en los Regímenes de Bienestar de la Unión Europea". Cuadernos de Relaciones Laborales, 29(1): 13-42. Doi: http:// dx.doi.org/10.5209/rev_CRLA.2011.v29.n1.1 
ROMAÑACH, Javier, LOBATO, Manuel.

2005 "Diversidad funcional, nuevo término para la lucha por la dignidad en la diversidad del ser humano", Foro de Vida Independiente. URL: <http://www.forovidaindependiente.org/files/documentos/pdf/diversidad_funcional.pdf $>$, acceso 27 de febrero de 2014.

SÁNCHEZ MALDONADO, José, MOLINA, Carmen (col.), RIVAS, Carlos (Col.).

2010 "La Ley de Dependencia: especial consideración a los aspectos financieros", en S. González Ortega, J. Codorniu, E. Sáenz et al., Informe sobre la Ley de Promoción de la Autonomía Personal y Atención a las personas en situación de dependencia. Barcelona: Fundación Democracia y Gobierno Local. Diputación de Barcelona. URL: <http://repositorio.gobiernolocal.es/xmlui/bitstream/handle/10873/688/ Sanchez_Maldonado_p_53_90.pdf?sequence=1>, acceso 27 de febrero de 2014 .

SANDAY, Peggy Reeves.

2013 "Un modelo para la etnografía de interés público: la conjunción de teoría, práctica, acción y cambio en un mundo globalizado." Revista de Antropología Social, 22: 199-232. Doi: http://dx.doi.org/10.5209/rev_RASO.2013.v22.43189.

SARASA, Sebastián.

2000 "La última red de servicios personales", en J. Adelantado (Coord.), Cambios en el Estado del bienestar. Políticas sociales y desigualdades en España, Barcelona: Icaria, 347-378.

2009 “El quart pilar de l'Estat del Benestar i el gat de Cheshire”, en M. Subirats (Coord.), Societat Catalana, 2009. Barcelona: Associació Catalana de Sociología, 83-99.

SHORE, Chris; WRIGHT, Susan.

1997 "Policy: a new field of anthropology", en C. Shore, S. Wright (Eds.), Anthropology of Policy. Critical Perspectives on Governance and Power. London: Routledge, 3-39.

SIMONAZZI, Annamaria.

2008 "Care Regimes and National Employment Models". Cambridge Journal of Economics, 10: 1-22. Doi: http://dx.doi.org/10.1093/cje/ben043.

SORONELLAS, Montserrat (Coord.).

2010 Familias en la emigración. Emociones, solidaridades y obligaciones en el espacio transnacional. Barcelona: Icaria.

UNGERSON, Clare.

1995 "Gender, Cash and Informal Care: European Perspectives and Dilemmas". Journal of Social Policy, 24 (1): 32-52, 1995. Doi: http://dx.doi.org/10.1017/ S004727940002451X.

WAERNES, Karl.

2001 "Sobre la racionalidad del cuidado", en S. Sasoon (Ed.), Las mujeres y el Estado. Madrid: Vindicación Feminista, 241-272. 